\title{
Review
}

\section{Principles of tumor immunosurveillance and implications for immunotherapy}

\section{Adrian F Ochsenbein}

\author{
Department of Clinical Research, University of Berne, Berne, Switzerland; and Institute of Medical Oncology, \\ Inselspital, Berne, Switzerland.
}

\begin{abstract}
Although antigen loss variants, major histocompatibility (MHC) class I down-regulation, or the expression of inhibitory molecules may explain the failure of immunosurveillance against some tumors, this seems not to apply for many other solid peripheral or lymphohematopoietic tumors. Why then is immunosurveillance so ineffective and can it be improved? This review focuses on one important aspect of tumor immunity, namely the relevance of antigen dose and localization. Immune responses in vivo are induced in organized lymphoid tissues, i.e., in lymph nodes and spleen. The antigen dose that reaches secondary lymphoid organs over time is a crucial parameter that drives antiviral and antitumoral immune responses. Tumors use various strategies to prevent efficient presentation of their antigens in lymphoid organs. A major obstacle to the induction of an endogenous tumor-specific cytotoxic T lymphocyte $(C T L)$ response is the inefficient presentation of tumor antigen on MHC class I molecules of professional antigenpresenting cells. Peripheral solid tumors that develop outside lymphoid organs are, therefore, often ignored by the immune system. In other situations, tumors - especially of lymphohematopoietic origin — may tolerize specific CTLs. Understanding tumor immunosurveillance is key to the design of efficient antitumor vaccines. Attempts to improve immunity to tumors include vaccination strategies to (a) provide the tumor antigen to secondary lymphoid organs using recombinant viruses or dendritic cells as carriers, (b) express costimulatory signals on tumor cells, or (c) improve the efficiency of cross-priming.

Cancer Gene Therapy (2002) 9, 1043-1055 doi:10.1038/sj.cgt.7700540
\end{abstract}

Keywords: immunosurveillance; tumor; immunotherapy; costimulation; cross-priming

$\mathrm{I}^{\mathrm{n}}$ nfectious pathogens may predominantly infect immunoincompetent young individuals and, therefore, endanger the species. The immune system coevolved with infectious diseases in a way that allows survival of the host and the pathogen. In contrast, because carcinomas and sarcomas usually arise in individuals beyond reproductive age, these tumors are more a problem for the individual patient than for the population as a whole. Thus, the immune system did not develop special strategies to protect against cancer; instead, tumors are fought by an immune system that has been shaped by infectious pathogens. Indeed, the immunobiology of cancer and infectious diseases may be overlapping, e.g., the recognition and elimination of both virus - infected and tumor cells seem to depend on similar mechanisms. The general means by which the immune system reacts against viruses and cancer are, therefore, discussed together in this review.

The immunological effector mechanisms necessary for the efficient control of a bacterial or viral infection are dependent upon the specific route of entry used by the infectious agent. A hematogenously spreading infectious

Received September 16, 2002.

Address correspondence and reprint requests to: $\mathrm{Dr}$ Adrian $F$ Ochsenbein, Fred Hutchinson Cancer Research Center, Clinical Research, D3-100, 1100 Fairview Avenue North, Seattle, WA 98109-1024, USA.

E-mail: aochsenb@fhcrc.org pathogen is best controlled by neutralizing antibodies. ${ }^{1}$ The protection of vital target organs by $\operatorname{IgM}$ and $\operatorname{IgG}$ antibodies is illustrated by infections with Streptococcus pneumoniae, Haemophilus influenzae, enteroviridae, measles, influenza, and poxvirus. ${ }^{2,3}$ In contrast, infections of peripheral solid organs with noncytopathic viruses such as hepatitis $\mathrm{B}$ and $\mathrm{C}$ virus in humans or lymphocytic choriomeningitis virus (LCMV) in mice are largely controlled by activated cytotoxic T lymphocytes (CTLs), which have the capacity to extravasate and enter the infected peripheral solid tissue; antibodies play virtually no role in this process. ${ }^{4}$

Solid tumors, including carcinomas and sarcomas, often express a cell-associated tumor antigen ${ }^{5,6}$ and, therefore, resemble viral infections of peripheral tissues in many ways. Similar to protection against noncytopathic viruses, the main effector mechanism of adaptive immunity to control peripheral tumors may be CTL, and antibodies seem to play only a limited role. Therefore, this review tries to define principles by which a tumor- or virus-specific CTL response is elicited and summarizes vaccination strategies being used to improve immunity to tumors.

\section{Immunosurveillance of tumors}

In the 1950s, the immunosurveillance hypothesis was formulated. ${ }^{7,8}$ It described that the immune system of the host 
recognizes antigens of newly arising tumors and eliminates these tumors before they become clinically evident. Progressive cancer was seen as a rare event in which the tumor cell escaped the efficient control of the immune system. Today, it is quite clear that the immune system does not play this central role in the control of early tumor development. ${ }^{9,10}$ However, the contribution of the host immune response and the relevance of $\mathrm{B}$ and $\mathrm{T}$ cells in tumor control are still poorly understood.

\section{Role of cytotoxic $T$ cells}

Clinically manifest tumors have obviously not been controlled efficiently by immunity. Many tumors apparently use various strategies to evade the recognition by CTL. Mechanisms such as major histocompatibility (MHC) class I down-regulation, antigen loss, antigen modulation, or the expression of inhibitory molecules may explain the failure of an endogenous immune response in tumor control. ${ }^{11-15}$ Nevertheless, various antigenic tumors, e.g., melanomas, renal cancers, or breast tumors, may successfully grow in an immunocompetent host. Tumor-infiltrating lymphocytes (TILs) have been found in many experimental models and have been isolated from human tumors. ${ }^{16,17}$ Their existence indicates that although an immune response was induced, it was insufficient to control or reject the tumor completely. However, other observations may suggest that the immunosurveillance of tumors may be of importance and sometimes is very efficient. For example, immunosuppression leads to a higher incidence of virally triggered tumors or tumors of lymphohematopoietic or vascular origin, but interestingly does not influence the incidence of the more common tumors such as breast cancer, colon cancer, or lung cancer. ${ }^{18-20}$ Evidence supporting only a limited role of the host's immune response against tumors was derived from observations that nude mice with impaired T- and Bcell development have a normal incidence of spontaneously arising tumors. ${ }^{21}$ However, nude mice are not completely deficient in $\mathrm{B}$ and $\mathrm{T}$ cells as they possess some limited residual T- and B-cell function. More recent experiments in mice deficient in either $R A G$ genes (thus lacking $\mathrm{T}$ and $\mathrm{B}$ cells) or STAT1 genes (thus lacking interferon-mediated pathways) revealed a higher incidence of spontaneous tumors. ${ }^{22}$ However, even RAG/STAT1 double knockout mice that lack important effector mechanisms of both adaptive and innate immunity developed tumors only late and the tumor incidence during the first year was comparable to controls, indicating an only limited efficiency of the endogenous immune response in controlling tumorigenesis. A higher incidence of chemically induced tumors in perforin-deficient mice indicates that the perforin pathway and probably $\mathrm{CD} 8^{+} \mathrm{T}$ cells may play a role in tumor immunosurveillance; ${ }^{23}$ however, only the incidence of spontaneous lymphohematopoietic but not solid tumors is increased in these mice. ${ }^{24}$

Together, these observations suggest that the host immune response may, in some situations, control tumors, but in others, especially against peripheral solid tumors, the endogenous immune response is often not an effective barrier for tumor growth.

\section{Role of antibodies}

In the course of most CTL-mediated immune responses, including antitumor immune responses, specific antibodies are also produced. In the last few years, the relative efficacy of antitumor antibodies for the treatment of certain breast cancers or B-cell lymphomas ${ }^{25}$ renewed the interest of immunologists in humoral antitumor responses. Antibodies are not toxic for a virus-infected cell or a tumor cell per se but act either by blocking vital signaling molecules on the cell surface or by a secondary effector mechanism including antibody-dependent cellular cytotoxicity (ADCC) or complement-dependent cytotoxicity (CDC). ${ }^{26}$

In mice, antimelanoma antibodies inhibit tumor growth in a FcyR-dependent manner. ${ }^{27}$ In addition, the importance of the $\mathrm{Fc}-\mathrm{Fc} \gamma \mathrm{R}$ interaction for antitumor activity was shown for the clinically important antibodies transtuzumab (Herceptin) and rituximab (Mabtera, Rituxan) as well as for intracerebral therapy with an anti-EGF receptor antibody in a brain tumor model. ${ }^{28,29}$ The antitumor effect of Herceptin and Rituxan was greatly reduced in mice that lack the activation receptors Fc $\gamma \mathrm{RI}$ and Fc $\gamma \mathrm{RIII}$, whereas disruption of the gene that encodes for the inhibitory receptor Fc $\gamma$ RIIB substantially enhanced antitumor activity. In contrast, evidence of a relevance of CDC is currently limited to in vitro experiments. Antibodies with improved ability to bind to the complement component $\mathrm{C} 1 \mathrm{q}$ have been created using site-directed mutagenesis. ${ }^{30}$ These antibodies mediated an enhanced CDC against target cells in vitro, but the relevance of $\mathrm{CDC}$ for the protection against tumors in vivo remains to be shown. Although ADCC seems to be an important effector mechanism of passively transferred monoclonal antibody, the physiological relevance of an endogenous antibody response to tumor antigens seems to be limited to very few experimental systems.

An interesting possibility is that antibodies influence the induction of cytotoxic $\mathrm{T}$ cells. The data on this topic are controversial. Antibodies have been shown to enhance cross-presentation of tumor antigens. Targeting antigen to Fc $\gamma \mathrm{R}$ promoted cross-presentation by several orders of magnitude in mouse bone marrow-derived dendritic cells (DCs $)^{31,32}$ and recent in vitro experiments suggested a role for antitumor antibodies in the induction of antitumor CTLs. Coating of myeloma cells with antisyndecan antibodies increased cross-presentation and cross - priming of the tumor antigens NY-ESO1 and MAGE $3{ }^{33}$ It is important to note here that the cross - priming of all these antigens was studied in vitro. In a mouse model, $\mathrm{CD} 8^{+} \mathrm{T}$-cell depletion prevented treatment of established solid tumors with antitumor mAbs, suggesting a role of antibodies in the induction of CTLs in vivo. ${ }^{34}$ In contrast, a study in B cell-deficient mice revealed that the induction of an antitumor response in the absence of $\mathrm{B}$ cells and antibodies is enhanced. ${ }^{35}$ It was speculated that antigen-presenting cells (APCs), such as B cells, macrophages, and DCs, compete for antigen. Taken together, antibodies may enhance or impair the induction of tumorspecific CTLs in different ways. The requirements for either of these processes and especially their relevance for the protection against tumors in vivo remain to be analyzed in clearly defined model situations. 


\section{Induction of T cells}

\section{Antigen dose and localization}

Lymphocytes, macrophages, and APCs perform their effector functions as single cells, but in order to activate naive CTL, they need to interact and collaborate in organized lymphoid tissue. ${ }^{36-39}$ The term organized lymphoid tissue defines structures such as follicles, marginal zone, germinal center, periarteriolar sheath, and red pulp. These anatomical structures determine the localization of antigen, cytokines, and bystander contacts through costimulatory molecules. Therefore, lymph nodes and the spleen provide the milieu necessary for lymphoid cell interactions and activation.

The localization and the amount of viral or tumor antigen that reaches secondary lymphoid organs over time are, therefore, crucial parameters for the induction of CTLs; ${ }^{40-43}$ antigens that never reach organized lymphoid tissues in a sufficient amount are ignored by the immune system. ${ }^{44,45}$ Several viruses avoid immunosurveillance simply by staying outside of lymphoid tissues. A classic example is Papilloma virus that infects basal layers of epidermal cells and replicates only in keratinocytes without infecting Langerhans' cells. ${ }^{46}$ Experimental evidence for the necessity of antigen reaching secondary lymphoid organs for the induction of a CTL response came from very early experiments. In 1957, Frey and Wenk ${ }^{47}$ showed that the sensitization of isolated skin flaps of guinea pigs is dependent on an intact draining lymph node and lymph vessel. Supporting evidence for the importance of the antigen localization was provided by experiments performed by Lafferty and Woolnough. ${ }^{48}$ They succeeded in transplanting allogeneic thyroid epithelial cells after depletion of passenger leukocytes under the kidney capsule. The graft did not induce an immune response but also did not tolerize the host immune system.

Diabetes models with a transgenic antigen expressed on islet cells are very informative for the role of the antigen localization in the induction of CTL. ${ }^{4,49}$ RIP-GP transgenic mice express the glycoprotein (GP) of LCMV under the ratinsulin promoter (RIP). These RIP-GP mice do not spontaneously develop diabetes. In contrast, if these mice are infected with replicating LCMV virus or immunized with DCs expressing LCMV-GP, they mount an LCMV-GPspecific CTL response and develop diabetes. ${ }^{44,49,50}$ These experiments illustrate that T cells specific for LCMV-GP are present, but because the antigen is expressed strictly outside secondary lymphoid organs and the antigen does not reach local lymph nodes in a sufficient quantity over a sufficient time period, no specific CTLs are induced and the peripheral antigen is ignored. Alymphoplastic mice (aly/aly) lack lymph nodes but possess a spleen with functionally normal CTL. ${ }^{41,51}$ Although aly/aly mice generated detectable, but reduced, CTL responses after infection with vaccinia virus and LCMV, the elimination of these viruses was either delayed or virtually impossible; irrespective of the dose or the route of infection, aly/aly mice developed life-long LCMV persistence and splenectomized aly/aly mice did not mount a CTL response at all after infection with $\mathrm{LCMV}^{41}$ More recently, it was shown that aly/aly mice are immunologically ignorant of a cardiac allograft. ${ }^{52}$ These results document the critical role of secondary lymphoid organs in the induction of naive T cells.

How may these results from experiments in autoimmunity and viral immunity models be translated to tumor immunity? Solid tumors arise from a single cell in the periphery (i.e., outside secondary lymphoid organs) and early in the development of the tumor, no or only few antigenexpressing tumor cells will reach secondary lymphoid organs. We recently showed for a lymphoma, sarcoma, carcinoma, and melanoma - each expressing the same model tumor antigen ( LCMV-GP) — that the migration of the tumor cells to secondary lymphoid organs is crucial for the induction of an immune response. ${ }^{42,53}$ Tumors regularly grew without inducing an LCMV-GP-specific CTL response if they were transplanted as solid tumor fragments. These antigenic peripheral solid tumors stayed strictly outside lymphoid organs and no tumor cells could be detected in local lymph nodes (Fig 1A). In contrast, if the same cells were injected as single cell suspension subcutaneously (s.c.), they reached local lymph nodes and, as a consequence, a specific CTL response was induced (Fig 1C). In aly/aly mice, tumor cells cannot reach local lymph nodes because they are absent. Therefore, in these mice, s.c. injected tumor cells in suspension did not induce a CTL response and tumors grew. In addition, the direct injection of the tumor cells into secondary lymphoid organs is $100-1000$ times more efficient in the induction of a tumor-specific immune response than a s.c. injection. ${ }^{40}$ Peripheral solid tumors also did not tolerize the immune system because immunization with replicating LCMV or with antigen-expressing DCs readily induced a tumorspecific CTL response. ${ }^{42,53}$ Importantly, even the tumor cells themselves induced an immune response in tumor-bearing mice when they reached secondary lymphoid organs. These experiments illustrate that ignorance of peripheral tumors may be one of the main obstacles to an efficient immunosurveillance of solid tumors. They also indicate that early trapping of tumor cells in secondary lymphatic organs is beneficial because it induces CTLs that reject the tiny tumors early. In contrast, late metastasis to lymphoid organs with histologically detectable tumor cells usually indicates a worsening prognosis. ${ }^{54}$ The fact that tumor cells are detectable in lymph nodes indicates that they have evaded recognition by the immune system. In addition to the welldocumented mechanisms such as antigen loss, MHC class I down-regulation, and the expression of inhibitory molecules, ${ }^{11}$ the formation of an isolating coat that separates naive CTLs from the tumor cells may explain the formation of lymph node metastasis ${ }^{42}$ (Fig 2). In the latter case, naive CTLs do not have contact with the tumor antigen and the tumor in the periphery is ignored by specific $\mathrm{CD}^{+} \mathrm{T}$ cells (Fig 1B).

CTLs respond to antigens that become transiently presented within organized lymphoid tissues for at least 35 days. In contrast, T cells do not react against antigens that are continuously present in lymphoid organs. ${ }^{55,56}$ Antigen that is continuously present in secondary lymphoid organs will activate and delete all $\mathrm{T}$ cells specific for that antigen. The process of activation followed by physical deletion of the $\mathrm{T}$ cells is termed exhaustion. Some noncytopathic 


\section{A) Ignorance I}

\section{B) Ignorance II}
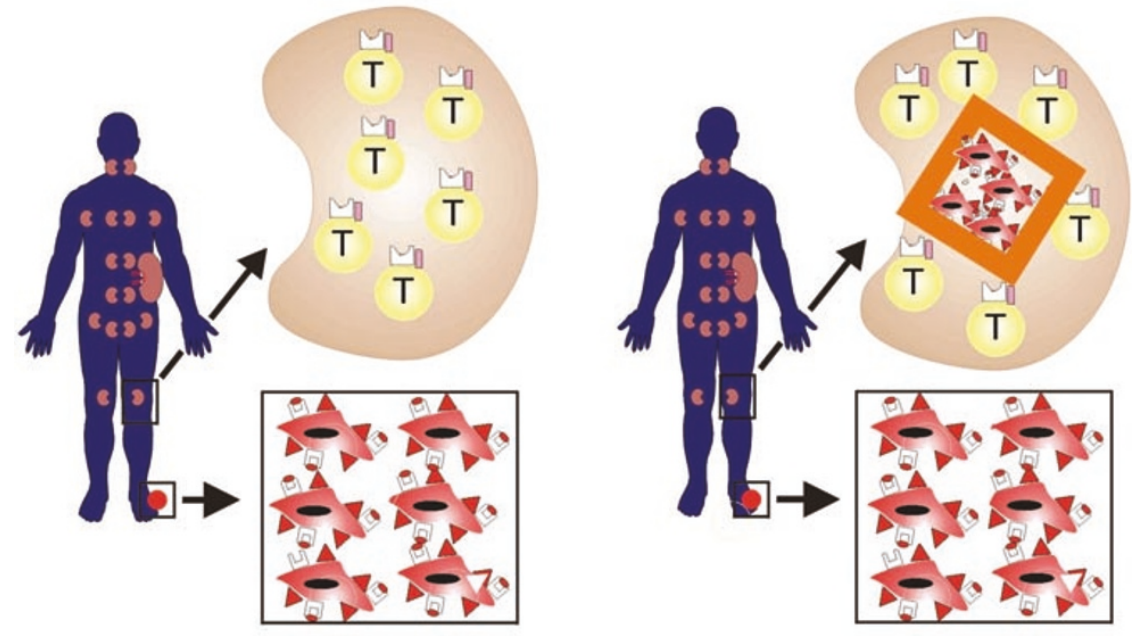

\section{C) Activation}

\section{D) Tolerance}
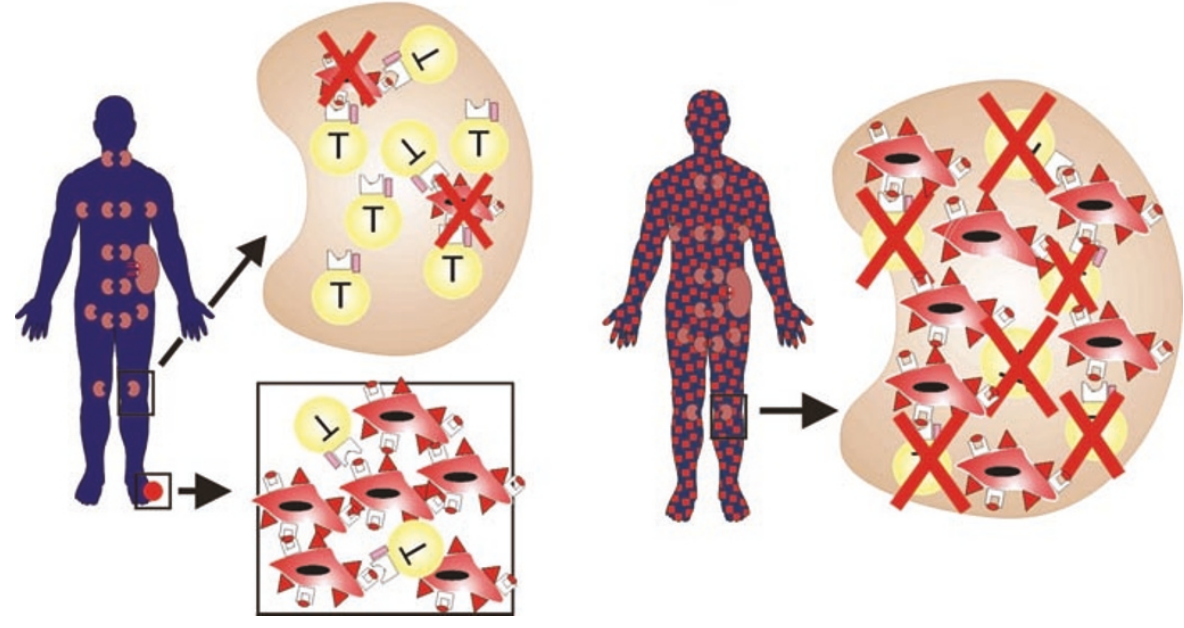

Figure 1 Regulation of the antitumoral immune response by tumor localization. A: A peripheral solid tumor develops outside secondary lymphoid organs and no or very few tumor cells reach local lymph nodes. B: Tumor cells reach local lymph nodes but they evade immune recognition. Shown is the escape from immune recognition by formation of an isolating coat but MHC class I down- regulation, loss of antigen, or the expression of inhibitory molecules by tumor cells in lymphoid organs also results in escape from immune recognition. C: A sufficient number of tumor cells in secondary lymphoid organs results in the activation of specific CTLs and in the elimination of the tumors cells that reach lymphoid organs (i.e., there are no tumor cells detectable by conventional histology). The outcome of the peripheral tumor depends on the relative numbers of activated CTLs and the tumor mass. D: A widespread lymphoma or leukemia results in the deletion of the specific CTL.

persistent infections that are transmitted from mother to offspring or an overwhelming infectious dose of a rapidly replicating virus in adults can lead to this form of tolerance. ${ }^{56}$ Lymphohematopoietic tumors develop within organized lymphoid tissues and should, therefore, induce an efficient immune response. That this may indeed be the case is illustrated by the fact that immunosuppression markedly increases the incidence of these tumors. ${ }^{20}$ Lymphomas and leukemias that escape immunosurveillance and become clinically evident may use strategies similar to those used by persistent noncytopathic viruses. The injection of a lymphoma cell line expressing LCMV-GP intravenously (i.v.) induced a specific immune response and the transferred lymphoma cells were routinely rejected. However, if a large number of lymphoma cells were injected $\left(>10^{7}\right)$, the specific cells were tolerized by exhaustion and the mice died of the lymphoma ${ }^{42}$ (Fig 1D). Comparably, studies addressing the role of $\mathrm{CD} 4^{+} \mathrm{T}$ cells in the control of a murine lymphoma revealed an induction of antigen-specific $\mathrm{CD}^{+}{ }^{+} \mathrm{T}$-cell tolerance early during tumor development. ${ }^{57}$

In summary, the discussed experiments reveal the following simple rules that determine immunoreactivity (Fig 3): (a) a low antigen dose in lymphoid organs is not sufficient to induce a CTL response and, as a consequence, antigens that strictly stay outside lymphoid organs are 


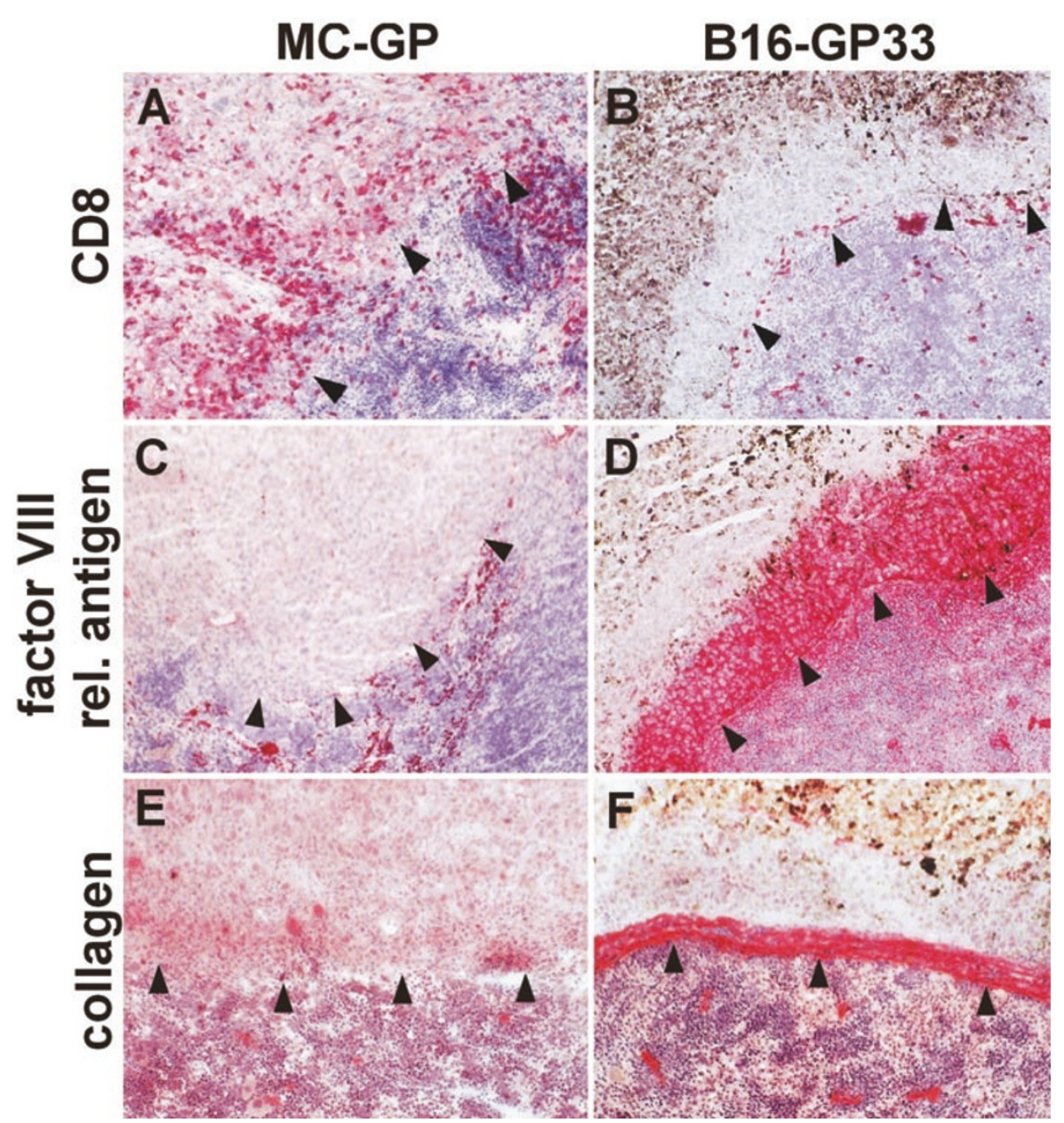

Figure 2 Formation of an isolating coat by a metastasis in lymphoid organs. MC-GP fibrosarcoma cells induce a CTL response when injected directly into the spleen (i.s. ). CD8 ${ }^{+} \mathrm{T}$ cells are intermixed with the tumor cells and they, therefore, can be directly stimulated by the tumor antigen expressed on MHC class I on the tumor cells (A,C,E). In contrast, B16-GP33 melanoma cells do not induce an immune response when injected i.s. B16-GP33 cells form a coat initially of factor VIII-related antigen (D) and later of collagen (F) that separates the tumor cells from CD8 ${ }^{+} \mathrm{T}$ cells (B). Arrows indicate the metastasis within the spleen. Reprinted with permission from Nature, ${ }^{42}$ copyright 2001, Macmillan.

immunologically ignored; (b) a sufficient antigen dose over a sufficiently long time period in lymphoid organs induces a specific CTL response; and (c) a high amount of antigen continuously present in lymphoid organs tolerizes the specific CTL response.

\section{Costimulation}

T-cell activation has been shown to require two distinct signals. Supporting evidence compatible with this hypothesis is derived mainly from in vitro studies, but also from some in vivo studies. ${ }^{58-63}$ Signal 1 is delivered by the interaction between the T-cell receptor (TCR) and antigenic peptides presented on MHC molecules. The second signal is provided by at least one of several antigen-nonspecific costimulatory signals, ${ }^{63,64}$ including the interaction of CD28 on T cells with B7 family molecules on professional APCs. TCR stimulation without involvement of second signals has been correlated with induction of T-cell anergy or deletion. ${ }^{58,60,63,64}$ Additional second signals include members of the TNFR family (CD40-CD40L, CD27-CD70, OX40-OX40L, 4-1BB-4-1BBL, and others $)^{65-68}$ as well as soluble molecules such as IL-2, IL-12, and IL-18 ${ }^{69}$ and molecules involved in cell adhesion and T-cell stimulation such as LFA-1 and ICAM-1. ${ }^{70}$ The two-signal hypothesis originally explained contact-dependent cooperation of $\mathrm{CD}^{+} \mathrm{T}$ cells and B cells ${ }^{58}$ but was then extended generally to induction of T cells. ${ }^{59}$ Although activation of $\mathrm{CD}^{+} \mathrm{T}$ cells may be less dependent on costimulation than activation of $\mathrm{CD}^{+}{ }^{+} \mathrm{T}$ cells, expression of costimulatory molecules or cytokines has been shown to variably enhance CTL activation and proliferation, ${ }^{64,69}$ and offers rationales to explain the lack of antitumor immunity as well as new possibilities for enhancement of such CTL responses. ${ }^{71,72}$ It is important and interesting to note that, whereas studies in $\mathrm{CD} 28^{-1-}$ or $\mathrm{B} 7^{-1-}$ mice have demonstrated that CD28B7 interactions enhance T-cell responses in lymphoid organs, the role of such interactions in solid peripheral 


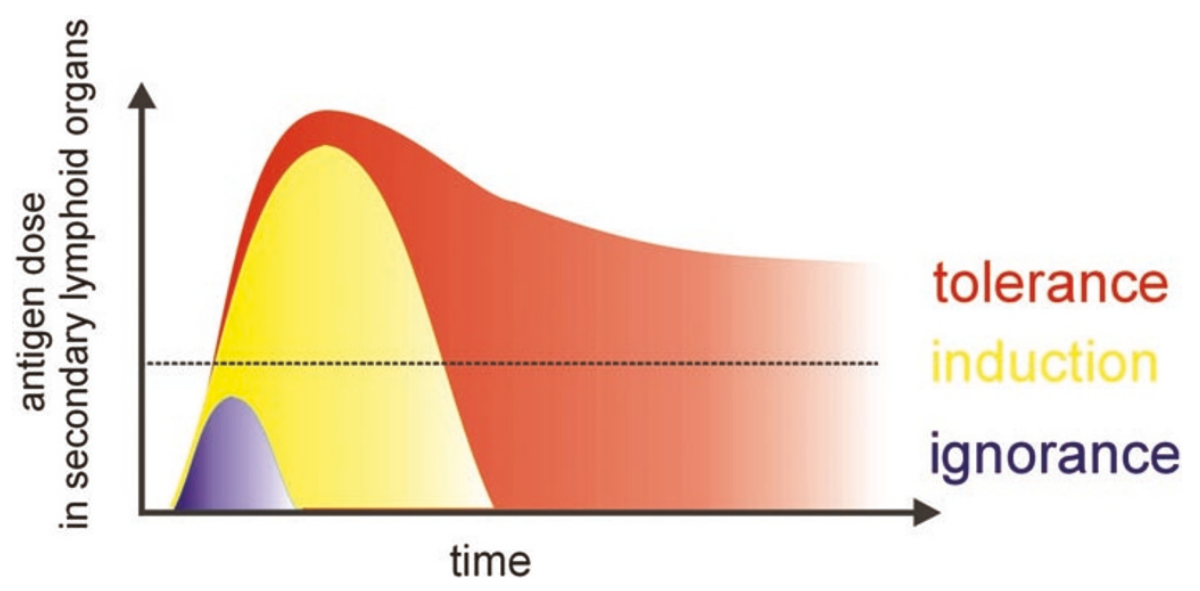

Figure 3 Antigen dose over time in secondary lymphoid organs determines the resulting CTL response. The horizontal dotted line determines the minimal amount of antigen necessary for the induction of a CTL response.

tissues is largely based on theoretical considerations and on indirect evidence based mainly on experiments with tumors. ${ }^{61,62}$

Experiments performed during the past 10 years have documented that expression of costimulatory signals on tumor cells improves immunogenicity in several murine tumor models as assessed by resistance against primary tumor establishment or more efficient protection against a tumor challenge. ${ }^{61,62,66,71,72}$ Nevertheless, eradication of already established peripheral tumors (i.e., growing for more than 8-10 days) by enhancement of costimulation was hardly ever observed. In contrast to these experimental tumor models that used injections of single cell suspensions, LCMV-GP and B7.1-expressing tumors did not induce a CTL response if they stayed outside of secondary lymphoid organs. ${ }^{42}$ Tumor antigen and second signal-expressing tumors transplanted as solid tumor fragment s.c. or injected s.c. into lymph node deficient aly/aly mice did not elicit a specific CTL response and the peripheral tumors were ignored by the immune system. In contrast, CTL priming in lymphatic organs in $\mathrm{CD} 28^{-1-}$ mice was reduced by a factor of about $1004^{42,74}$

One might argue that in vivo, one costimulatory signal expressed alone on a peripheral tumor may not be sufficient to activate naive $\mathrm{T}$ cells and several different second signals may be necessary. The experiments with aly/aly mice indicate, however, that both abundance of costimulatory signals including B7.1, B7.2, CD40L, and CD70, ${ }^{62-65}$ and soluble factors such as $\mathrm{IL}-2^{69}$ are offered only within the anatomic structure of secondary lymphoid organs in a manner necessary and sufficient for interaction of naive $\mathrm{CD}^{+} \mathrm{T}$ cells with antigen-expressing cells in a bystander or a linked manner ${ }^{75}$ - probably together with $\mathrm{CD}^{+} \mathrm{T}$ cells - to result in a CTL response.

The question then remains as to what is the contribution of a costimulatory molecule expressed on a peripheral tumor to the overall antitumor immune response. A relatively more efficient rejection of $\mathrm{B}^{+}$tumor cells injected as cell suspensions has been demonstrated in various studies previously. ${ }^{61,62,72}$ Adoptive transfer experiments revealed that, although LCMV-GP and B7.1 - expressing solid tumors did not induce specific CTL outside of secondary lymphoid organs, the expression of a second signal on the tumor enhanced/maintained already primed CTL responses. ${ }^{42}$ This is compatible with reports on the role of B7 in the effector phase of a CTL response in a peripheral tumor ${ }^{76,77}$ and may well extend also to experimental autoimmune encephalitis ${ }^{78}$ and to results on enhanced diabetes in transgenic mice expressing a specific CTL target peptide and B7 in islet cells. ${ }^{79}$

Taken together, many observations indicate that tumors expressing costimulatory molecules are usually rejected more efficiently than control tumors. ${ }^{62,72,75,77}$ However, most analyses did not rigorously distinguish induction from enhanced maintenance of effector $\mathrm{T}$ cells. Costimulatory signals expressed within secondary lymphoid organs shift the dose-response curve for the induction of naive CTL to lower antigen doses, but a single costimulatory signal expressed on a peripheral tumor is not sufficient to activate naive CTL. Additional expression of costimulatory signals on tumor cells seems not to increase their immunogenicity within secondary lymphoid organs. However, a key role of costimulatory signals on peripheral tumors may be to enhance/maintain already primed T-cell responses against the tumor. ${ }^{42,73,76,77}$ This peripherally enhanced/maintained immune response in tumors expressing costimulatory molecules is apparently able to more efficiently control the tumors at an early stage.

\section{Cross-priming by professional APCS}

Two pathways of antigen presentation have been described in vivo. Exogenous antigens are taken up by professional APC (pAPC) including DCs, B cells, and macrophages. They are then processed, loaded on MHC class II molecules, and presented to specific $\mathrm{CD}^{+} \mathrm{T}$ cells. Cytoplasmatic proteins or foreign proteins that are produced in the cytoplasm, i.e., viral proteins, reach the endoplasmatic reticulum by a TAP-dependent mechanism. In the RER, they are loaded on MHC class I and presented as 8- to 10-aa-long peptides to $\mathrm{CD} 8^{+} \mathrm{T}$ cells. 
Soon after the revelation of MHC restriction, $\operatorname{Bevan}^{80}$ described that the two pathways may not be strictly separated by demonstrating that mice immunized with cells expressing foreign minor histocompatibility antigens mounted a self class I-restricted response even if the cells lacked the restricting class I molecule. Since then, various studies with $\mathrm{H}-\mathrm{Y}$ and other minor histocompatibility antigens, with tumor antigens, and with viral antigens have demonstrated a phenomenon that is compatible with cross-priming or cross-presentation on MHC class I. ${ }^{9,81-85}$ In vitro experiments clearly indicated that DCs process exogenous cell debris and present the peptides on MHC class I. This process may be even more efficient for apoptotic cells than for necrotic cells. ${ }^{82}$ The molecular mechanisms of this process have been analyzed in detail. These include regurgitation of peptides produced in the endocytic pathway and exogenous loading on MHC class I, antigen in phagolysosomes gaining access to the cytosol by the chaperoning of heat shock proteins (HSPs), and direct entry to the cytosol by macropinocytosis. ${ }^{86}$ However, high antigen doses have to be used to reach MHC class I presentation in vitro. ${ }^{82,87-89}$ Antigen presentation on MHC class II is achieved more easily and with lower antigen doses. The question, therefore, remains if cross-priming is also of relevance in vivo and if conditions similar to the in vitro experiments are reached in vivo.

In vivo, cross-presentation has been analyzed with minor histocompatibility differences. It was shown that minor histocompatibility antigens, together with $\mathrm{H}-2^{\mathrm{b}}$ on cells, injected into $\mathrm{F} 1$ (bxd) mice prime CTLs that are $\mathrm{H}$ $2^{\mathrm{d}}$-restricted. ${ }^{80,90,91}$ But in none of these cases has it been shown that a protein or gene product within the $\mathrm{H}-2^{\mathrm{b}}$ cell actually was processed and reexpressed through class I on the F1 cell in association with $\mathrm{H}-2^{\mathrm{d}}$. What happens in these minor histocompatible antigen situations is, therefore, unclear at the molecular level. Cross-presentation has been claimed to be responsible for tolerance and activation in experimental systems showing that APC and CTL do necessarily have to express the same $\mathrm{H}-2$ restriction for activation of CTLs. ${ }^{92}$ However, the interpretation drawn from those experiments that MHC class I-restricted antigens are presented by pAPC is not necessarily correct. pAPCs have to present $\mathrm{MHC}$ class II-restricted antigens to $\mathrm{CD} 4^{+} \mathrm{T}$ cells to provide help. ${ }^{93}$ If this pathway is blocked (by CD4 $4^{+}$ $\mathrm{T}$-cell depletion or by producing chimeras with allogeneic bone marrow), $\mathrm{CD} 8^{+} \mathrm{T}$-cell priming is no longer possible. In addition, experiments showing cross-priming in OVAtransgenic mice were usually done with TCR-transgenic T cells. ${ }^{94}$ The relevance of this process in a nontransgenic situation with low frequencies of naive $\mathrm{T}$ cells, therefore, remains open. Experiments by Huang et $\mathrm{al}^{92}$ with a colon carcinoma cell line transfected with influenza nucleoprotein (CT26-NP, H- $2^{\mathrm{b}}$ ) showed that these cells primed $\mathrm{H}-2^{\mathrm{d}}$ NP336-restricted CTL in F1 (bxd) mice. However, specific lysis of $\mathrm{H}-2^{\mathrm{d}}$ NP336-restricted CTL was very low (10$20 \%$ at an E:T of 100:1) and a comparison with the efficiency of direct priming by the tumor cells in lymphoid organs was not possible in this experimental system. The role of cross - priming on the peptide level in vivo was assessed in a comparable experimental situation using LCMV-GP and
NP-expressing splenocytes and tumor cells. $\left(\mathrm{H}-2^{\mathrm{b}} \times \mathrm{H}-2^{\mathrm{d}}\right)$ F1 mice were analyzed for the generation of $\mathrm{H}-2^{\mathrm{d}}-$ and $\mathrm{H}-2^{\mathrm{b}}$-restricted CTL after immunization with splenocytes from mice that express the LCMV-GP under the $\mathrm{H}-2 \mathrm{~K}^{\mathrm{b}}$ promoter and LCMV-GP or NP-transfected MC57G (fibrosarcoma, H-2 ${ }^{\mathrm{b}}$ ), D2 (fibrosarcoma, H-2 ${ }^{\mathrm{d}}$ ), EL4 (lymphoma, $\mathrm{H}-2^{\mathrm{b}}$ ), and P815 (mastocytoma, $\mathrm{H}-2^{\mathrm{d}}$ ) tumor cells. ${ }^{42}$ The resulting CTL response was, in all cases, limited to the haplotype of the immunizing cells, indicating that the efficiency and physiological relevance of cross-priming in vivo are very low or absent. In addition, in an allogeneic bone marrow transplantation model, Shlomchik et $\mathrm{al}^{95}$ showed that despite the presence of numerous donor APCs, only host-derived APCs presented minor histocompatibility antigens in vivo and initiated graft-versus -host disease. Thus, cross-priming of recipient minor histocompatibility antigens on donor APC was inefficient.

Taken together, cross-presentation may be induced in vitro to load APC with exogenous proteins and may be observed also in vivo in TCR - transgenic systems but is very inefficient when analyzed on a peptide level in a nontransgenic situation, indicating that cross-presentation in vivo is not impossible but rather the exception than the rule. The lack of relevant cross-priming may explain why most peripheral solid tumors do not induce an efficient antitumor immune response.

\section{Implications for immunotherapy of tumors}

Understanding the reasons why tumors usually do not induce an efficient CTL response is a key to designing more efficient CTL-based vaccine strategies. ${ }^{96,97}$ A crucial step in the diagnostic process before initiating immunotherapy is to determine whether immunosurveillance failed because of immunological ignorance or because of a form of immunological tolerance including the deletion of the specific T cells. In the first situation, specific CTLs are present in secondary lymphoid organs and can be activated by an active immunization protocol, as discussed below. If, however, immunosurveillance fails because of exhaustion of the specific CTL, an active immunization strategy obviously will be inefficient and the adoptive transfer of ex vivo activated and expanded $\mathrm{T}$ cells may be a promising approach. ${ }^{98}$ The overall rejection success depends on the relative kinetics of tumor cell numbers ( or tumor size, influenced by growth rate and several other tumor parameters) versus kinetics and relative numbers of effector $T$ cells over time. An initial maximal reduction of the tumor or leukemia load by chemotherapy or surgery is, therefore, crucial for the success of an immunization protocol.

\section{Providing antigen to secondary lymphoid organs}

Various strategies and carriers have been used to provide antigen to the patients' immune system as a vaccine. ${ }^{96}$ DCs are assigned a central role in the presentation of the antigen with most vaccination strategies. One possibility that has already been tested extensively in clinical phases I and II trials is the injection of DCs that are loaded in vitro with the specific tumor antigen or peptide. ${ }^{99}$ DCs migrate through the 
afferent lymph to secondary lymphoid organs and present the antigen to specific CTL. Similarly, the injection of peptide s.c. or intradermally (i.d.) $)^{100-102}$ or the immunization with DNA ${ }^{103}$ will result in the presentation of antigen by host APC. It is interesting to note that most of these immunization protocols are more efficient if the antigen is directly injected into lymphoid organs. ${ }^{104}$ A factor of $100-$ $1000 \times$ less peptide or recombinant DNA is necessary to induce an immune response when directly injected into lymphoid organs. However, a limitation of all these immunization strategies is the difficulty in maintaining a highenough antigen concentration in lymphoid organs over a sufficient time period. Strategies to overcome this problem include prime-boost protocols that vary from immunizations once every week to once every 3 months. ${ }^{105,106}$ What then are the requirements that a possible therapeutic vaccine against an established tumor has to fulfill? Experiments using DC that constitutively express the LCMV-GP33 for immunization protocols against tumors ${ }^{53,107}$ but also for the induction of diabetes in the RIP-GP model ${ }^{50}$ highlighted the importance of a continuous presence of antigen within lymphoid organs for at least 7-14 days. Repetitive exposure to antigen within this early time period increased the frequency of specific CTLs whereas booster immunizations after this first expansion did not further increase CTLp frequency (Fig 4A-D). However, repetitive booster injections of antigen-expressing DC kept specific CTL activated with the ability to lyse target cells ex vivo. In a murine model with established LCMV-GP-expressing tumors, mice were immunized once with 200 plaque-forming units (pfu) of LCMV-WE i.v. or $10^{5}$ LCMV-GP33-41-expressing DCs or with $2 \times 10^{6}$ single MC-GP tumor cells injected s.c. that reach draining lymph nodes and spleen. By these immunizations of short duration ( $<7$ days $)$, tumor growth was retarded only negligibly (Fig 4E). A comparable minimal effect of a single vaccination had been shown in the case of a LCMVGP-positive insulinoma. ${ }^{108}$ If, however, mice were immunized either with a high dose of $2 \times 10^{6}$ pfu of LCMV-WE causing a prolonged and widely spreading infection with long-term CTL activation, or alternatively by repeated injections of LCMV-GP-expressing DC or MC-GP in 2 -to 5 -day intervals for 3 weeks, most tumor fragments failed to grow further and eventually disappeared completely (Fig 4F). Thus, an antigen-driven prolonged CTL response is needed to reject peripheral tumors, initially for maximal expansion of the CTLp frequency and later to maintain the specific CTLs activated and able to lyse target cells.

\section{Providing costimulatory signals}

The two-signal hypothesis has led to experimental immunization protocols providing additional costimulatory signals. ${ }^{62,66,71,72}$ Solid tumors usually do not express costimulatory signals. Transfection of carcinoma and sarcoma cells with B7 or other costimulatory molecules resulted in greater immunogenicity and tumor cells expressing second signals were usually rejected more efficiently. ${ }^{61}$ Similarly, genes that encode B7 molecules were included into recombinant DNA and viral vectors for antigen-specific vaccination. ${ }^{109}$ As outlined above, these additional costimulatory signals may not necessarily improve the initial priming
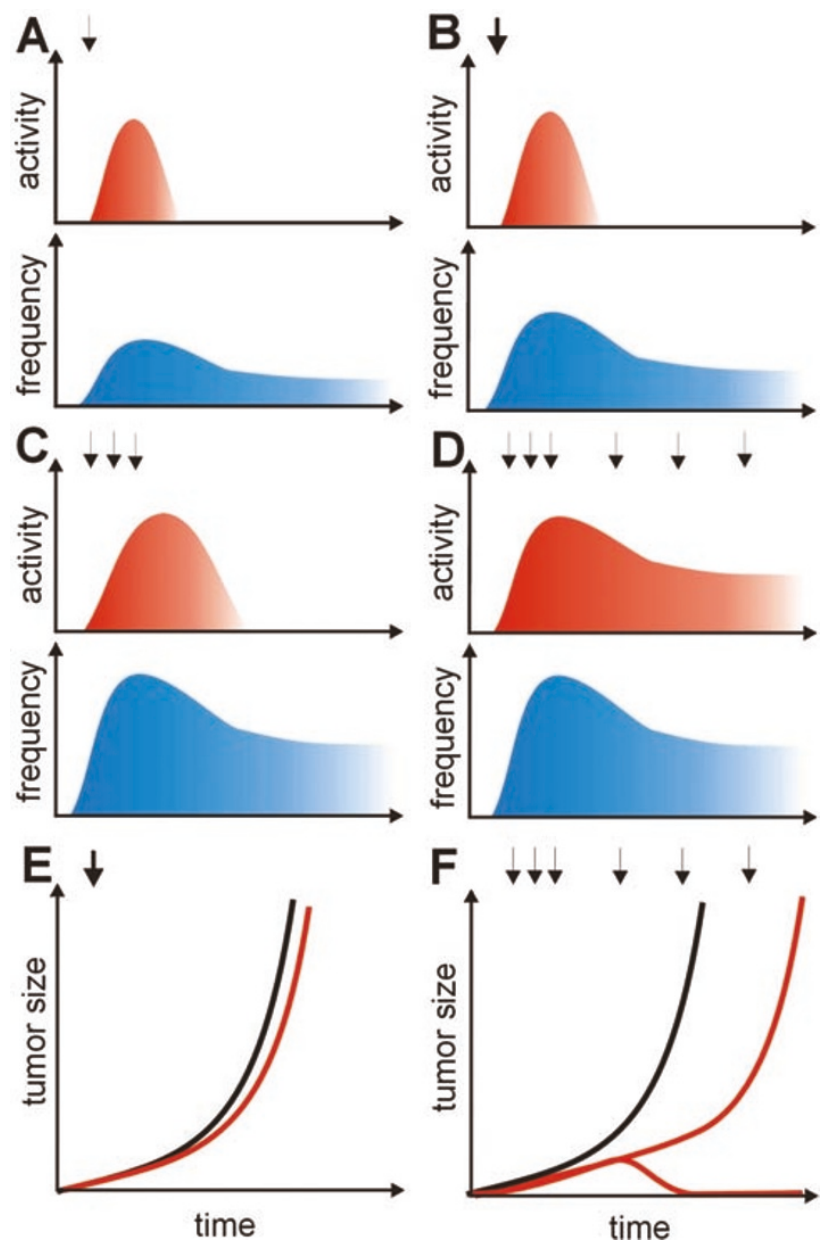

Figure 4 Antigen requirements to induce a protective antitumor CTL response. A: A single immunization with an intermediate dose of antigen induces a limited expansion of CTLp and the activity of these cells is limited to a short period of time. B: An increase in the immunizing antigen dose only marginally increases the CTLp frequency and the activation status of the CTL. C: A prolonged persistence of antigen in lymphoid organs - as is reached by repetitive immunization - is necessary to increase the CTLp frequency. D: Booster immunizations after the initial expansion are necessary to keep CTL activated. E: A single immunization with antigen-expressing DCs does not change the tumor growth kinetic (red) in comparison to the control group (black). F: Repetitive immunizations (initially for full expansion of CTL and later to maintain CTL in an activated status) are necessary for the rejection of established tumors. Tumors that are too big in size for complete rejection reach a stable disease as long as antigen is continuously provided by repetitive booster vaccination. Experiments supporting these concepts were published in ,Refs. [50,53,107].

of a $\mathrm{T}$ cell within lymphoid organs but instead maintain or even expand antigen-experienced CTL in the periphery. Another way to augment a specific immune response is to provide antibodies specific for a costimulatory molecule that mediates mitogenic signals for $\mathrm{T}$-cell activation and growth. ${ }^{73,110}$ In murine tumor models, the administration of anti-4-1BB mAb led to the impressive regression of established poorly immunogenic sarcomas and highly tumorigenic mastocytomas. ${ }^{73}$ Because primed but not naive 
$T$ cells express $4-1 \mathrm{BB}$, it is most likely that the administration of the antibody augmented an undetectable but weak antitumor response by maintaining/amplifying primed $T$ cells in the periphery. In addition, recent evidence indicates that stimulating antibodies specific for some costimulatory molecules might even be able to break anergic tolerance. ${ }^{111}$ Therefore, promising approaches include strategies enhancing costimulation by directly transfecting tumor cells in peripheral tumors in vivo with virus vectors encoding a second signal or by providing costimulatory antibodies. However, it is important to emphasize that although improving costimulation will shift the dose-response curve for the induction of specific CTL to lower antigen doses, it will not overcome the requirement that the tumor antigen has to be present in lymphoid organs for the induction of the specific immune response.

\section{Improving the efficiency of cross-priming}

The lack of relevant cross - priming explains why peripheral antigens on tumors or on $\beta$-cells of the pancreatic islet are ignored by the immune system. ${ }^{42,44,45}$ However, developing strategies to enhance cross-priming of tumor antigens would be very attractive for vaccination protocols in order to overcome the problem that restricting epitopes have to be characterized for each $\mathrm{MHC}$ molecule. One strategy to improve the uptake of exogenous antigens and its processing and presentation on MHC class I is to incubate DCs with large amounts of antigen in vitro (i.e., concentrations that would never be reached under physiological conditions in vivo ). ${ }^{82,87-89}$ It seems sufficient to introduce the antigen to the cytosol to reach peptide processing and a TAP-dependent presentation on MHC class I. Therefore, in vitro electroporation $^{112}$ or fusiogenic liposomes ${ }^{113}$ allow the entry of exogenous material to the MHC class I pathway of antigen presentation. Liposomes containing the tumor antigen may also be used for in vivo priming of CTLs, especially if the access to the cytosol is increased by the addition of lysteriolysin $\mathrm{O}$ to the liposomes, which allows the lysis of the phagolysosome and the entry of the tumor antigen into the cytosol. ${ }^{114}$ In contrast, more recent evidence suggests that receptor-mediated endocytosis is more efficient and requires lower amounts of antigen. Antigens from apoptotic bodies, ${ }^{82}$ complexed to $\mathrm{IgG}^{31}$ or coupled to HSPs, ${ }^{115,116}$ are endocytosed through scavenger, Fc $\gamma$, or HSP receptors, respectively, and cross-presented by DCs to CTLs. These mechanisms may be employed to load exogenous antigen on MHC class I molecules in vitro and potentially also in vivo. Recently, Jeannin et al. ${ }^{117}$ showed that whole antigen coupled to a Klebsiella pneumoniae protein (kpOmpA) specifically bound to a receptor on professional APCs and resulted in the delivery of antigen into the MHC class I presentation pathway. Simultaneous immunization with kpOmpA coupled to ovalbumin resulted in protection against a tumor challenge with ovalbumin-expressing tumor cells.

Viral vectors for the induction of antitumor immunity

Considering the reasons why the endogenous immune response fails to protect against tumors, recombinant viruses seem an ideal candidate to immunize against tumors. Viruses often infect and replicate within professional APCs and they reach high titers in secondary lymphoid organs. By infecting pAPC, they overcome the problem of inefficient crosspriming, their antigens are presented by pAPC in the context of costimulatory molecules, and the infected pAPC migrates to local lymph nodes. Therefore, there is wide interest in the use of vaccines composed of attenuated viruses or bacteria as carriers of tumor antigens. ${ }^{118-120}$ More than 20 different RNA and DNA viruses as well as bacteria are used as vectors including poxviruses (especially the highly attenuated strain Ankara, as well as fowlpox and canarypox) but also adenoviruses and herpesviruses. ${ }^{121}$ Each of these vectors has various advantages and disadvantages and currently no viral vector can clearly be favored over the others. These attenuated viruses usually infect human cells but do not replicate or do so only to a very limited extent in vivo. Attenuation of these viruses is necessary to prevent disease induction in the immunized patient and potentially to prevent horizontal spread of the recombinant virus. However, attenuation also limits their use as vaccine carriers because their short in vivo persistence and limited production of tumor antigen prevent them from inducing and sustaining antitumor CTL responses. In addition, after the initial immunization, a cell- and antibody-based immune response against the viral carrier is elicited, which limits the possibility of booster immunization with the same recombinant virus. This limitation has led to the concept of cycling different viral vectors in prime-boost protocols. ${ }^{106}$ Indeed, a marked enhancement of immunization potency has been observed with prime-boost protocols using different recombinant viruses, e.g., fowlpox followed by vaccinia virus. ${ }^{122}$ Taken together, an ideal viral vector for tumor immunotherapy should combine prolonged persistence and replication in vivo with minimal risk for disease induction in the patient and horizontal spread - a goal that is difficult to reach.

\section{Conclusion}

Understanding why the endogenous immune response fails to control tumorigenesis is key to improving antitumor immunity. The antigen dose localization concept for the induction of CTLs proposes that the immunosurveillance of peripheral tumors fails because of immunological ignorance, whereas lymphohematopoietic tumors may induce tolerance to evade immune recognition. In the situation of immunological ignorance of a tumor, a vaccine efficiently delivering tumor antigen to secondary lymphoid organs may lead to tumor control and eradication if the tumor load is neither too great nor too difficult to reach. Only continued stimulation of either endogenous host or in vitro expanded and adoptively transferred effector T cells will likely be sufficient to lead to rejection of tumors quickly enough before the selection of escape mutants. Alternatively, in a situation where a widely spreading tumor induces tolerance, high-avidity $\mathrm{T}$ cells may not be available due to either anergy or deletion. These concepts are being evaluated in both animal models and clinical trials in order to better understand tumor immunity. It 
is hoped that such information, along with other recent advances in understanding tumor immunosurveillance, will make it possible to develop more specific and novel therapeutic approaches to treat cancer.

\section{Acknowledgments}

I thank Rolf Zinkernagel and William Ho for critically reading the manuscript. A F O was supported by the Swiss National Science Foundation (Grant 1078).

\section{References}

1. Bachmann MF, Zinkernagel RM. Neutralizing anti-viral B cell responses. Annu Rev Immunol. 1997;15:235-270.

2. Fenner F, McAuslan BR, Mims CA, Sambrook J, White DO. The Biology of Animal Viruses. London: Academic Press; 1974.

3. Baumgarth N, Herman OC, Jager GC, Brown LE, Herzenberg LA, Chen J. B-1 and B-2 cell-derived immunoglobulin M antibodies are nonredundant components of the protective response to influenza virus infection. $J$ Exp Med. 2000;192: $271-280$.

4. Zinkernagel RM, Bachmann MF, Kündig TM, Oehen S, Pircher H, Hengartner H. On immunological memory. Annu Rev Immunol. 1996;14:333-367.

5. Boon T, Coulie PG, Van DE. Tumor antigens recognized by T cells. Immunol Today. 1997;18:267-268.

6. Old LJ. Tumor immunology: the first century. Curr Opin Immunol. 1992;4:603-607.

7. Burnet FM. Cancer: a biological approach. Br Med J. 1957; 1:779-786.

8. Burnet FM. Immunological aspects of malignant disease. Lancet. 1967;1:1171-1174.

9. Pardoll D. T cells and tumours. Nature. 2001;411:10101012.

10. Smyth MJ, Godfrey DI, Trapani JA. A fresh look at tumor immunosurveillance and immunotherapy. Nat Immunol. 2001;2:293-299.

11. Griffith TS, Brunner T, Fletcher SM, Green DR, Ferguson TA. Fas ligand-induced apoptosis as a mechanism of immune privilege. Science. 1995;270:1189-1192.

12. Garrido F, Ruiz-Cabello F, Cabrera T, et al. Implications for immunosurveillance of altered HLA class I phenotypes in human tumours. Immunol Today. 1997;18:89-95.

13. Chen JJ, Sun Y, Nabel GJ. Regulation of the proinflammatory effects of Fas ligand (CD95L). Science. 1998;282:17141717.

14. Benitez R, Godelaine D, Lopez-Nevot MA, et al. Mutations of the beta2-microglobulin gene result in a lack of HLA class I molecules on melanoma cells of two patients immunized with MAGE peptides. Tissue Antigens. 1998;52: 520-529.

15. Johnson A, France J, Sy MS, Harding CV. Down-regulation of the transporter for antigen presentation, proteasome subunits and MHC class I in tumor cell lines. Cancer Res. 1998;58:3660-3667.

16. Rosenberg SA, Spiess P, Lafreniere R. A new approach to the adoptive immunotherapy of cancer with tumor-infiltrating lymphocytes. Science. 1986;233:1318-1321.

17. Whiteside TL. Tumor-infiltrating lymphocytes in human solid tumors. Immunol Ser. 1994;61:137-148.

18. Hiesse C, Rieu P, Kriaa F, et al. Malignancy after renal transplantation: analysis of incidence and risk factors in 1700 patients followed during a 25 -year period. Transplant Proc. 1997;29:831-833.

19. Newstead CG. Assessment of risk of cancer after renal transplantation. Lancet. 1998;351:610-611.

20. Kelly DM, Emre S, Guy SR, Miller CM, Schwartz ME, Sheiner PA. Liver transplant recipients are not at increased risk for nonlymphoid solid organ tumors. Cancer. 1998;83: $1237-1243$.

21. Stutman O. Immunodepression and malignancy. Adv Cancer Res. 1975;22:261-422.

22. Shankaran V, Ikeda H, Bruce AT, et al. IFNgamma and lymphocytes prevent primary tumour development and shape tumour immunogenicity. Nature. 2001;410:1107-1111.

23. van den Broek MF, Kägi D, Ossendorp F, et al. Decreased tumor surveillance in perforin-deficient mice. J Exp Med. 1996;184:1781-1790.

24. Smyth MJ, Thia KY, Street SE, MacGregor D, Godfrey DI, Trapani JA. Perforin-mediated cytotoxicity is critical for surveillance of spontaneous lymphoma. J Exp Med. 2000; 192:755-760.

25. Houghton AN, Scheinberg DA. Monoclonal antibody therapies - a "constant" threat to cancer. Nat Med. 2000;6:373374.

26. Carter P. Improving the efficacy of antibody-based cancer therapies. Nat Rev Cancer. 2001;1:118-129.

27. Clynes R, Takechi Y, Moroi Y, Houghton A, Ravetch JV. Fc receptors are required in passive and active immunity to melanoma. Proc Natl Acad Sci USA. 1998;95:652-656.

28. Clynes RA, Towers TL, Presta LG, Ravetch JV. Inhibitory Fc receptors modulate in vivo cytotoxicity against tumor targets. Nat Med. 2000;6:443-446.

29. Sampson JH, Crotty LE, Lee S, et al. Unarmed, tumorspecific monoclonal antibody effectively treats brain tumors. Proc Natl Acad Sci USA. 2000;97:7503-7508.

30. Idusogie EE, Presta LG, Gazzano-Santoro H, et al. Mapping of the C1q binding site on rituxan, a chimeric antibody with a human IgG1 Fc. J Immunol. 2000;164:4178-4184.

31. Regnault A, Lankar D, Lacabanne V, et al. Fcgamma receptor-mediated induction of dendritic cell maturation and major histocompatibility complex class I-restricted antigen presentation after immune complex internalization. J Exp Med. 1999;189:371-380.

32. Machy P, Serre K, Leserman L. Class I-restricted presentation of exogenous antigen acquired by Fcgamma receptormediated endocytosis is regulated in dendritic cells. Eur $J$ Immunol. 2000;30:848-857.

33. Dhodapkar KM, Krasovsky J, Williamson B, Dhodapkar MV. Antitumor monoclonal antibodies enhance cross-presentation of cellular antigens and the generation of myeloma-specific killer T cells by dendritic cells. J Exp Med. 2002;195:125133.

34. Dyall R, Vasovic LV, Clynes RA, Nikolic-Zugic J. Cellular requirements for the monoclonal antibody-mediated eradication of an established solid tumor. Eur J Immunol. 1999;29: 30-37.

35. Qin Z, Richter G, Schuler T, Ibe S, Cao X, Blankenstein T. B cells inhibit induction of $\mathrm{T}$ cell-dependent tumor immunity. Nat Med. 1998;4:627-630.

36. Ford WL. Lymphocyte migration and immune responses. Prog Allergy. 1975;19:1-59.

37. Mackay CR. T cell memory: the connection between function, phenotype and migration pathways. Immunol Today. 1991;12: $189-192$.

38. Zinkernagel RM, Ehl S, Aichele P, Oehen S, Kündig TM, Hengartner H. Antigen localisation regulates immune re- 
sponses in a dose- and time-dependent fashion: a geographical view of immune reactivity. Immunol Rev. 1997;156: 199-209.

39. Goodnow CC. Chance encounters and organized rendezvous. Immunol Rev. 1997;156:5-10.

40. Kündig TM, Bachmann MF, DiPaolo C, et al. Fibroblasts as efficient antigen-presenting cells in lymphoid organs. Science. 1995;268:1343-1347.

41. Karrer U, Althage A, Odermatt B, et al. On the key role of secondary lymphoid organs in antiviral immune responses studied in alymphoplastic (aly/aly) and spleenless (Hox11-/-) mutant mice. J Exp Med. 1997;185:21572170.

42. Ochsenbein AF, Sierro S, Odermatt B, et al. Roles of tumour localization, second signals and cross priming in cytotoxic $\mathrm{T}$ cell induction. Nature. 2001;411:1058-1064.

43. Zinkernagel RM, Hengartner H. Regulation of the immune response by antigen. Science. 2001;293:251-253.

44. Ohashi PS, Oehen S, Buerki K, et al. Ablation of "tolerance" and induction of diabetes by virus infection in viral antigen transgenic mice. Cell. 1991;65:305-317.

45. Chen L. Immunological ignorance of silent antigens as an explanation of tumor evasion. Immunol Today. 1998;19:2730.

46. Frazer IH. Cell-mediated immunity to papilloma viruses. Papillomavirus Rep. 1992;3:53-58.

47. Frey JR, Wenk P. Experimental studies on the pathogenesis of contact eczema in the guinea-pig. Int Arch Allergy. 1957;11: $81-100$.

48. Lafferty KJ, Woolnough J. The origin and mechanism of allograft rejection. Immunol Rev. 1997;35:231-262.

49. Oldstone MB, Nerenberg M, Southern P, Price J, Lewicki H. Virus infection triggers insulin-dependent diabetes mellitus in a transgenic model: role of anti-self (virus) immune response. Cell. 1991;65:319-331.

50. Ludewig B, Odermatt B, Landmann S, Hengartner $\mathrm{H}$, Zinkernagel RM. Dendritic cells induce autoimmune diabetes and maintain disease via de novo formation of local lymphoid tissue. J Exp Med. 1998;188:1493-1501.

51. Miyawaki S, Nakamura Y, Suzuka H, et al. A new mutation, aly, that induces a generalized lack of lymph nodes accompanied by immunodeficiency in mice. Eur J Immunol. 1994;24:429-434

52. Lakkis FG, Arakelov A, Konieczny BT, Inoue Y. Immunologic "ignorance" of vascularized organ transplants in the absence of secondary lymphoid tissue. Nat Med. 2000;6: 686-688.

53. Ochsenbein AF, Klenerman $\mathrm{P}$, Karrer U, et al. Immune surveillance against a peripheral solid tumor fails because of immunological ignorance. Proc Natl Acad Sci USA. 1999;96: 2233-2238.

54. DeVita VT, Hellmann S, Rosenberg SA. In: DeVita VT, Hellmann S, Rosenberg SA, eds. Cancer, Principles and Practice of Oncology. Philadelphia, USA: Lippincott Raven; 1998:Vol. 5

55. Webb S, Morris C, Sprent J. Extrathymic tolerance of mature T cells: clonal elimination as a consequence of immunity. Cell. 1990;63:1249-1256.

56. Moskophidis D, Lechner F, Pircher H, Zinkernagel RM. Virus persistence in acutely infected immunocompetent mice by exhaustion of antiviral cytotoxic effector T cells. Nature. 1993;362:758-761.

57. Staveley-O'Carrol K, Sotomayor E, Montgomery J, et al. Induction of antigen -specific T cell anergy: an early event in the course of tumor progression. Proc Natl Acad Sci USA. 1998;95:1178-1183.
58. Bretscher P, Cohn M. A theory of self-nonself discrimination. Science. 1970;169:1042-1049.

59. Lafferty KJ, Cunningham AJ. A new analysis of allogeneic interactions. Aust J Exp Biol Med Sci. 1975;53:27-42.

60. Schwartz RH. A cell culture model for T lymphocyte clonal anergy. Science. 1990;248:1349-1356.

61. Chen L, Ashe S, Brady WA, et al. Costimulation of antitumor immunity by the B7 counterreceptor for the $\mathrm{T}$ lymphocyte molecules CD28 and CTLA-4. Cell. 1992;71: $1093-1102$

62. Townsend SE, Allison JP. Tumor rejection after direct costimulation of $\mathrm{CD}^{+}{ }^{+} \mathrm{T}$ cells by $\mathrm{B} 7$-transfected melanoma cells. Science. 1993;259:368-370.

63. Matzinger P. Tolerance, danger, and the extended family. Annu Rev Immunol. 1994;12:991-1045.

64. Chambers CA, Allison JP. Co-stimulation in T cell responses. Curr Opin Immunol. 1997;9:396-404.

65. Cella M, Scheidegger D, Palmer-Lehmann K, Lane P, Lanzavecchia A, Alber G. Ligation of CD40 on dendritic cells triggers production of high levels of interleukin-12 and enhances $\mathrm{T}$ cell stimulatory capacity: $\mathrm{T}-\mathrm{T}$ help via APC activation. J Exp Med. 1996;184:747-752.

66. Diehl L, Den BA, Schoenberger SP, et al. CD40 activation in vivo overcomes peptide-induced peripheral cytotoxic $\mathrm{T}$ lymphocyte tolerance and augments anti-tumor vaccine efficacy. Nat Med. 1999;5:774-779.

67. Hintzen RQ, de JR, Lens SM, van LR. CD27: marker and mediator of T-cell activation? Immunol Today. 1994;15: $307-311$.

68. Watts TH, DeBenedette MA. T cell co-stimulatory molecules other than CD28. Curr Opin Immunol. 1999;11:286-293.

69. Smith KA. Interleukin 2. Annu Rev Immunol. 1984;2:319333.

70. Shimizu Y, van SG, Horgan KJ, Shaw S. Roles of adhesion molecules in $\mathrm{T}$-cell recognition: fundamental similarities between four integrins on resting human T cells (LFA-1, VLA-4, VLA-5, VLA-6) in expression, binding, and costimulation. Immunol Rev. 1990;114:109-143.

71. Liebowitz DN, Lee KP, June CH. Costimulatory approaches to adoptive immunotherapy. Curr Opin Oncol. 1998;10:533541.

72. Hellstrom KE, Hellstrom I, Chen L. Can co-stimulated tumor immunity be therapeutically efficacious? Immunol Rev. 1995; 145:123-145.

73. Melero I, Shuford WW, Newby SA, et al. Monoclonal antibodies against the 4-1BB T-cell activation molecule eradicate established tumors. Nat Med. 1997;3:682-685.

74. Shahinian A, Pfeffer K, Lee KP, et al. Differential T cell costimulatory requirements in CD28-deficient mice. Science. 1993;261:609-612.

75. Yang G, Mizuno MT, Hellstrom KE, Chen L. B7-negative versus B7-positive P815 tumor. Differential requirements for priming of an antitumor immune response in lymph nodes. J Immunol. 1997; 158:851-858.

76. Ramarathinam L, Castle M, Wu Y, Liu Y. T cell costimulation by $\mathrm{B} 7 / \mathrm{BB} 1$ induces $\mathrm{CD} 8 \mathrm{~T}$ cell-dependent tumor rejection: an important role of $\mathrm{B} 7 / \mathrm{BB} 1$ in the induction, recruitment, and effector function of antitumor T cells. J Exp Med. 1994; 179:1205-1214.

77. Maric M, Zheng P, Sarma S, Guo Y, Liu Y. Maturation of cytotoxic $\mathrm{T}$ lymphocytes against a B7-transfected nonmetastatic tumor: a critical role for costimulation by B7 on both tumor and host antigen-presenting cells. Cancer Res. 1998; 58:3376-3384

78. Chang TT, Jabs C, Sobel RA, Kuchroo VK, Sharpe AH. Studies in B7-deficient mice reveal a critical role for B7 
costimulation in both induction and effector phase of experimental autoimmune encephalomyelitis. $J$ Exp Med. 1999;190:733-740.

79. Harlan DM, Hengartner H, Huang ML, et al. Mice expressing both B7-1 and viral glycoprotein on pancreatic beta cells along with glycoprotein-specific transgenic $\mathrm{T}$ cells develop diabetes due to a breakdown of T-lymphocyte unresponsiveness. Proc Natl Acad Sci USA. 1994;91:3137-3141.

80. Bevan MJ. Cross-priming for a secondary cytotoxic response to minor $\mathrm{H}$ antigens with $\mathrm{H}-2$ congenic cells which do not cross-react in the cytotoxic assay. J Exp Med. 1976;143: $1283-1288$

81. Carbone FR, Kurts C, Bennet SRM, Miller JFAP, Heath WR. Cross-presentation: a general mechanism for CTL immunity and tolerance. Immunol Today. 1998;19:368-373.

82. Albert ML, Sauter B, Bhardwaj N. Dendritic cells acquire antigen from apoptotic cells and induce class I-restricted CTLs. Nature. 1998;392:86-89.

83. Sigal LJ, Crotty S, Andino R, Rock KL. Cytotoxic T-cell immunity to virus-infected non-haematopoietic cells requires presentation of exogenous antigen. Nature. 1999;398: $77-80$.

84. Heath WR, Carbone FR. Cross-presentation in viral immunity and self-tolerance. Nat Rev Immunol. 2001;1:126134.

85. Steinman RM, Turley S, Mellman I, Inaba K. The induction of tolerance by dendritic cells that have captured apoptotic cells. J Exp Med. 2000;191:411-416.

86. Heath WR, Carbone FR. Cross-presentation, dendritic cells, tolerance and immunity. Annu Rev Immunol. 2001;19:4764.

87. Berard F, Blanco P, Davoust J, et al. Cross-priming of naive CD8 T cells against melanoma antigens using dendritic cells loaded with killed allogeneic melanoma cells. J Exp Med. 2000;192:1535-1544.

88. Shen Z, Reznikoff G, Dranoff G, Rock KL. Cloned dendritic cells can present exogenous antigens on both MHC class I and class II molecules. J Immunol. 1997;158:2723-2730.

89. Kurts C, Miller JF, Subramaniam RM, Carbone FR, Heath WR. Major histocompatibility complex class I-restricted cross - presentation is biased towards high dose antigens and those released during cellular destruction. J Exp Med. 1998; 188:409-414

90. Gordon RD, Mathieson BJ, Samelson LE, Boyse EA, Simpson E. The effect of allogeneic presensitization on $\mathrm{H}-\mathrm{Y}$ graft survival and in vitro cell-mediated responses to H-Y antigen. $J$ Exp Med. 1976;144:810-820.

91. Matzinger P, Bevan MJ. Induction of H-2-restricted cytotoxic T cells: in vivo induction has the appearance of being unrestricted. Cell Immunol. 1977;33:92-100.

92. Huang AY, Golumbek P, Ahmadzadeh M, Jaffee E, Pardoll D, Levitsky H. Role of bone marrow-derived cells in presenting MHC class I-restricted tumor antigens. Science. 1994;264: 961-965.

93. Toes RE, Ossendorp F, Offringa R, Melief CJ. CD4 T cells and their role in antitumor immune responses. J Exp Med. 1999; $189: 753-756$.

94. Kurts C, Heath WR, Carbone FR, Allison J, Miller JFAP, Kosaka H. Constitutive class I-restricted exogenous presentation of self antigens in vivo. J Exp Med. 1996;184:923930.

95. Shlomchik WD, Couzens MS, Tang CB, et al. Prevention of graft versus host disease by inactivation of host antigenpresenting cells. Science. 1999;285:412-415.

96. Pardoll DM. Spinning molecular immunology into successful immunotherapy. Nat Rev Immunol. 2002;2:227-238.
97. Smyth MJ, Godfrey DI, Trapani JA. A fresh look at tumor immunosurveillance and immunotherapy. Nat Immunol. 2001;2:293-299.

98. Riddell SR, Greenberg PD. Principles for adoptive T cell therapy of human viral diseases. Annu Rev Immunol. 1995;13: $545-586$.

99. Nestle FO, Banchereau J, Hart D. Dendritic cells: on the move from bench to bedside. Nat Med. 2001;7:761-764.

100. Jager E, Gnjatic S, Nagata Y, et al. Induction of primary NYESO-1 immunity: $\mathrm{CD}^{+} \mathrm{T}$ lymphocyte and antibody responses in peptide-vaccinated patients with NY-ESO- ${ }^{+}$ cancers. Proc Natl Acad Sci. 2000;97:12198-12203.

101. Parmiani G, Castelli C, Dalerba P, et al. Cancer immunotherapy with peptide-based vaccines: what have we achieved? Where are we going? J Natl Cancer Inst. 2002; 94:805-818

102. Coulie PG, Karanikas V, Colau D, et al. A monoclonal cytolytic T-lymphocyte response observed in a melanoma patient vaccinated with a tumor-specific antigenic peptide encoded by gene MAGE-3. Proc Natl Acad Sci USA. 2001; 98:10290-10295.

103. Reyes-Sandoval A, Ertl HC. DNA vaccines. Curr Mol Med. 2001;1:217-243.

104. Maloy KJ, Erdmann I, Basch V, et al. Intralymphatic immunization enhances DNA vaccination. Proc Natl Acad Sci USA. 2001;98:3299-3303.

105. Marchand $\mathrm{M}$, van $\mathrm{BN}$, Weynants $\mathrm{P}$, et al. Tumor regressions observed in patients with metastatic melanoma treated with an antigenic peptide encoded by gene $M A G E-3$ and presented by HLA-A1. Int J Cancer. 1999;80:219-230.

106. Ramshaw IA, Ramsay AJ. The prime-boost strategy: exciting prospects for improved vaccination. Immunol Today. 2000;21:163-165.

107. Ludewig B, Ochsenbein AF, Odermatt B, Paulin D, Hengartner $\mathrm{H}$, Zinkernagel RM. Immunotherapies with dendritic cells directed against tumor antigens shared with normal host cells results in severe autoimmune disease. $J$ Exp Med. 2000;191:795-804.

108. Speiser DE, Miranda R, Zakarian A, et al. Self antigens expressed by solid tumors do not efficiently stimulate naive or activated T cells: implications for immunotherapy. $J$ Exp Med. 1997; 186:645-653.

109. Kim JJ, Bagarazzi ML, Trivedi N, et al. Engineering of in vivo immune responses to DNA immunization via codelivery of costimulatory molecule genes. Nat Biotechnol. 1997;15:641 646.

110. Weinberg AD, Rivera MM, Prell R, et al. Engagement of the OX-40 receptor in vivo enhances antitumor immunity. J Immunol. 2000;164:2160-2169.

111. Bansal-Pakala P, Jember AG, Croft M. Signaling through OX40 (CD134) breaks peripheral T-cell tolerance. Nat Med. 2001;7:907-912.

112. Chen W, Carbone FR, McCluskey J. Electroporation and commercial liposomes efficiently deliver soluble protein into the MHC class I presentation pathway. Priming in vitro and in vivo for class I-restricted recognition of soluble antigen. $J$ Immunol Methods. 1993;160:49-57.

113. Nakanishi T, Hayashi A, Kunisawa J, et al. Fusogenic liposomes efficiently deliver exogenous antigen through the cytoplasm into the MHC class I processing pathway. Eur $J$ Immunol. 2000;30:1740-1747.

114. Mandal M, Lee KD. Listeriolysin $O$-liposome-mediated cytosolic delivery of macromolecule antigen in vivo: enhancement of antigen-specific cytotoxic $\mathrm{T}$ lymphocyte frequency, activity, and tumor protection. Biochim Biophys Acta. 2002;1563:7-17. 
115. Binder RJ, Han DK, Srivastava PK. CD91: a receptor for heat shock protein gp96. Nat Immunol. 2000;1:151-155.

116. Schild H, Arnold-Schild D, Lammert E, Rammensee HG. Stress proteins and immunity mediated by cytotoxic $\mathrm{T}$ lymphocytes. Curr Opin Immunol. 1999;11:109-113.

117. Jeannin P, Renno T, Goetsch L, et al. OmpA targets dendritic cells, induces their maturation and delivers antigen into the MHC class I presentation pathway. Nat Immunol. 2000;1: 502-509.

118. Carroll MW, Overwijk WW, Chamberlain RS, Rosenberg SA, Moss B, Restifo NP. Highly attenuated modified vaccinia virus Ankara (MVA) as an effective recombinant vector: a murine tumor model. Vaccine. 1997;15:387-394.

119. Elzey BD, Siemens DR, Ratliff TL, Lubaroff DM. Immunization with type 5 adenovirus recombinant for a tumor antigen in combination with recombinant canarypox virus (ALVAC) cytokine gene delivery induces destruction of established prostate tumors. Int J Cancer. 2001;94:842-849.

120. Velders MP, McElhiney S, Cassetti MC, et al. Eradication of established tumors by vaccination with Venezuelan equine encephalitis virus replicon particles delivering human papillomavirus 16 E7 RNA. Cancer Res. 2001;61:78617867.

121. Ada G. Vaccines and vaccination. $N$ Engl J Med. 2001;345: $1042-1053$

122. Irvine KR, Chamberlain RS, Shulman EP, Surman DR, Rosenberg SA, Restifo NP. Enhancing efficacy of recombinant anticancer vaccines with prime/boost regimens that use two different vectors. J Natl Cancer Inst. 1997;89:15951601. 